$\Phi=\Phi$

\title{
Knowledge, attitude and practices of male condom use among male employees, 50 years and older, at a diamond mining company in southern Namibia
}

\author{
Phillemon K Nakathingo ${ }^{1}$, Wondwossen Lerebo ${ }^{1}$, Brian van Wyk ${ }^{1}$, Vistolina Nuuyoma ${ }^{2 *}$ \\ ${ }^{1}$ School of Public Health, University of the Western Cape, South Africa \\ ${ }^{2}$ School of Nursing, Southern Campus, University of Namibia, Namibia \\ *Corresponding author E-mail: vistolina.nuuyoma@gmail.com
}

\begin{abstract}
The HIV and AIDS pandemic has been characterised as the greatest health and development challenge ever to confront humanity, and is one of the great moral curses of our time. The pandemic has hit sub-Saharan Africa, and Namibia is one of the countries which are badly affected. In Namibia, the focus has been on the population aged 15 to 49 years. Hence, this study looks at older men in terms of it being a neglected population.

A descriptive, cross-sectional survey utilizing a quantitative research approach was applied. Data were collected through face-to-face interviewing 105 randomly selected male employees aged 50 years and older. Data were captured in MS Excel and then imported into SPSS version 16.0. The level of statistical significance was set at 0.05 .

This study revealed that respondents' knowledge about male condoms appeared to be moderate (52.4\%). About $92.4 \%$ stated that correct and consistent use of male condoms prevents HIV transmission. A larger percentage $(85.1 \%)$ of respondents disagreed that older men do not need to learn how to use a condom. A high percentage of respondents suggested that HIV-positive individuals should use condoms every time they have sexual intercourse.

Men aged 50 years and older are not at risk of contracting HIV due to lack of knowledge of male condom use. Thus, to minimize the likelihood of HIV infection, targeted interventions including peer education programmes were suggested in order to strengthen the practice and attitudes.
\end{abstract}

Keywords: Male Condom Use; Mining Company; Southern Namibia; HIV/AIDS Prevention; Male Employees.

\section{Introduction}

The HIV and AIDS pandemic has been characterised as the greatest health and development challenge ever to confront humanity, and as one of the great moral curses of our time (The World Bank, 2004). HIV and AIDS is not only a public health issue, but also a defined development problem of our era. The Joint United Nations Programme for HIV and AIDS (USAIDS \& WHO, 2009) reported that about 33.4 million people were living with HIV worldwide in 2008. This number increased to 36.7 million by the end of 2015 (WHO, 2016).

The burden of the HIV epidemic varies greatly between countries and regions.

Sub-Saharan Africa is the region with the greatest burden of HIV/AIDS, and the number of people living with HIV continues to rise (USAIDS \& WHO, 2009). Although new HIV infections have decreased by the end of 2015, sub-Saharan Africa was badly hit by the virus, and accounted for nearly $70 \%$ of people living with HIV globally (WHO, 2016). Namibia is among the 10 countries in the world with the highest HIV prevalence. It was estimated at $18.8 \%$ by $2010,18.2 \%$ by 2012 , and $16.9 \%$ by 2014 (MoHSS, 2014). In Namibia the impact of the HIV/AIDS epidemic is deep, multi-sectoral and intergenerational. It is estimated that 250,942 adults and children were living with HIV in Namibia in 2014 (MoHSS, 2014). As a result of HIV infection, it is also esti- mated that there were 3,100 HIV-related deaths in Namibia in 2015 (UNAIDS, 2016) and this is close to $30 \%$ of reported deaths. More than $80 \%$ of the Namibian population in age category 15 years and above understand key preventative behaviour relating to HIV/AIDS - such as abstaining from sex, remaining faithful to one uninfected partner, and the consistent and correct use of a condom (MoHSS, 2013). In addition to HIV education, condom distribution has been a priority in preventing the spread of HIV in Namibia. However, many continue to believe misconceptions about HIV/AIDS, in addition to having a low and inconsistent use of condoms. Preventative knowledge related to condoms varies by region. For example, only $71.3 \%$ of men in the !Kharas region knew that using a condom can prevent HIV transmission, compared to $91.1 \%$ in both the Khomas and Ohangwena regions (MoHSS, 2013). However, in spite of availability, distribution and education - condom use remains low and inconsistent (MoHSS, 2013). Furthermore, monitoring consistent and correct use remains a challenge in Namibia.

Economic and social migration are known to influence and facilitate the spread of HIV (Rivers \& Aggleton, 1999). Men who travel often or who are separated from their families and communities for an extended period (such as migrant workers) are at high risk of contracting HIV (Lamptey \& Gayle, 2001). This is because they tend to have a higher number of multiple and concurrent sexual partners. Thus, mobility and migration are both individual and structural risk factors (Pedian et al. 2008). 
A study among mine workers in Namibia on their knowledge, attitude and practices in terms of HIV and AIDS has indicated general negative attitudes with regard to condom use (Grotzinger, 2006). In another study, $67 \%$ of mine workers in Namibia knew that condom use prevents the spread of HIV and other STIs, but only $40 \%$ of them reported using condoms regularly (Hyde, 2007). Barriers to condom use identified by other studies include being in a permanent and stable relationship, fear of a partner, and the use of other contraceptives (i.e. pills or injectables). Unavailability of condoms at times, and also partner refusal, were reported among both white (62\%) and blue-collar (48\%) groups (Hyde, 2007).

\subsection{Research problem}

In Namibia very little research has been done on male condom use among older men - particularly those working in the Namibian mining sector. This is despite the fact that they work away from their families for a long time. Most mining is conducted at sites far from communities, so forcing workers to live apart from their families for extended periods of time. The miners often resort to commercial sex, and many become infected with HIV and spread that infection to their spouses and communities when they return home (Bollinger \& Stover, 1999). Although the HIV prevalence rate is perceived to be equally high in the older population, most studies on HIV/AIDS and sexual behaviour in Namibia have so far focused on those less than 49 years of age (MoHSS, 2013). Neglecting older adults above the age of 50 years could be related to assumptions that they are not at risk of HIV, as they are no longer sexually active (Negin et al. 2012). It is against this background that this study focuses on the knowledge, attitude, and practices of condom use among older men as a neglected population - in order to design targeted intervention. The findings of this study could be used to plan and implement interventions specifically for men above the age of 50 years in mining areas and other settings.

\subsection{Research aim}

The aim of the study was to assess the knowledge, attitude and practices of male condom use among employees aged 50 years and older at a mining company in southern Namibia.

\subsection{Objectives}

The objectives of the study were, for male employees aged 50 years and older, to:

- Measure the knowledge about condom use

- Describe attitudes in terms of condom use

- Describe sexual practices of condom use.

\section{Methodology}

\subsection{Study design}

The study used a quantitative, descriptive and a cross-sectional survey. Surveys enable researchers to measure many variables and to test multiple hypotheses (Maree, 2016). Therefore, surveys were the selected research method as they are appropriate for assessing knowledge, attitude and practices.

\subsection{Study setting}

Oranjemund is located in the Namib Desert on the edge of the Orange River and the Atlantic Ocean, in the far south of Namibia. This is a restricted diamond area under the Diamond Act, Act No. 13 of 1999. Since the discovery of diamonds in this area about 100 years ago and ultimately the establishment of the Oranjemund town, diamond mining activities have been the dominant employment opportunity in Oranjemund. Due to the colonial legacy of a migrant labour system, to date, most NAMDEB (Namdeb Diamond Corporation) employees are from northern Namibia. Many of those employees live in hostels for single men and do not live with their spouses or children.

The study was conducted at Mining Area One (MA1), at the NAMDEB mine, in Oranjemund. MA1 was chosen because this is where most of the employees were: about $70 \%$ of the total NAMDEB workforce.

\subsection{Study population and sampling}

The study population comprised 143 male miners aged 50 years and older who were on permanent and short-term contracts. Using computer software and Raosoft sample-size calculation, a sample size of 105 was determined as a study population. The study expected a condom use rate of $80 \%$, and thus it was considered that the sample size of 105 randomly selected employees would give a $95 \%$ level of confidence, and that the sample would be within the $5 \%$ margin of error for the true population prevalence.

A random sampling method was then used to draw the sample-size study population. This minimised the chance of unrepresentativeness of the study population - thereby reducing sampling bias (De Vos et al. 2011). With assistance from the $\mathrm{Hu}-$ man Resource Department, all male employees aged 50 and above were allocated numbers next to their names and then put in the drawing box. Employees whose numbers were chosen were asked to voluntarily participate in the study. Where a selected employee refused to participate or left employment, another randomly selected employee complying with the sample criteria was taken as a replacement.

\subsection{Data collection}

Data were collected in February 2010, during the period of two weeks. Standardised structure, interview-administered questionnaires were used to collect data. This enabled employees with no and low literacy to answer questions easily when interviewed. It further reduced measurement bias because all questions are standardised. The principal researcher was assisted by two trained assistant researchers to conduct the interviews. Some questionnaires were translated from English into Oshiwambo, as most older employees speak and understand the language.

\subsection{Data analysis}

Before data analysis, the questionnaires were coded for easy classification of answers. After coding, data were entered into Microsoft Excel and checked for possible errors before being imported into the "Statistical Package for the Social Sciences" SPSS version 16.0 for analysis. The proportion of demographic data such as age, employment category, educational level, marital status and its association, as well as knowledge, attitude and practices, were summarised using frequencies and percentages. The level of statistical significance was set at 0.05 .

\subsection{Reliability and validity}

To ensure validity and reliability, the questionnaire was designed with the help of the project supervisors, who are also experts in the field. Moreover, the initial questionnaire was piloted on 10 NAMDEB employees who were not going to take part in the study. Following the piloting, the researcher met with the employees to receive feedback on the questionnaire, and this feedback was also shared with the project supervisors. No major shortcomings were reported from the pilot study. In addition to the pilot study, other measures used in the study to ensure validity, were the use of random sampling and the calculation of sampling size.

\subsection{Ethical considerations}

Ethical clearance was obtained from the senate research committee at the University of the Western Cape. In addition, a second ethical clearance was sought and granted from NAMDEB hospital 
management. Informed consent was obtained from each participant before data collection. This means that no participant was forced to take part in the research without their consent. Furthermore, no identification information was required on the completed questionnaires - so as to ensure confidentiality of respondents. Study respondents were also informed that participation was voluntary and one could withdraw any time without giving reasons to the researcher. All data were kept secure, and only the researchers and research assistants and relevant individuals like the statistician had access to the information.

\section{Results}

\subsection{Description of study participants}

The mean age of the sample population was 54.5 years and ranged from 50 to 59 years.

Most $(89.5 \%)$ respondents were married (table 1). Just under half $(49.6 \%)$ of the respondents had secondary education, $(27.6 \%)$ had primary education, and $(24.8 \%)$ had tertiary educational training. A high percentage of respondents $(73.3 \%)$ were unskilled employees, for example those working in the field and mine plant as bedrock cleaners, machine operators and plant attendants - while $26.7 \%$ were skilled employees like engineers, secretaries and foremen who work in offices.

A small percentage of respondents $(22.91 \%)$ lived with their wives or partners, while a larger percentage $(77.1 \%)$ lived in hostels for single men.

Table 1: Participants' Socio-Demographic Characteristics

\begin{tabular}{lcc}
\hline Variables & Frequency & Percentages (\%) \\
\hline Marital status & & \\
Single & 11 & 10.5 \\
Married & 94 & 89.4 \\
& & \\
Job Category & & \\
Unskilled employee & 77 & 73.3 \\
Skilled employee & 28 & 26.7 \\
Educational level & & \\
Primary education & 29 & 27.6 \\
Secondary education & 50 & 49.6 \\
Tertiary education & 26 & 24.8 \\
Living with partner/wife & & \\
Yes & & 22.9 \\
No & 24 & 77.1 \\
\hline
\end{tabular}

\subsection{Knowledge about male condoms}

Knowledge about condoms in this study was classified into two categories: "knowledgeable" (should respondents answer correctly to seven or more of the nine questions about condom knowledge) and "insufficient knowledge" (should the respondents provide correct answers to less than seven of the questions).

A high percentage $(94.3 \%)$ of the respondents indicated that the use of male condoms is an important and integral part of an "Abstinence, Be faithful and Condom use" (ABC) strategy for HIV prevention.

About $(92.4 \%)$ stated that correct and consistent use of male condoms prevents HIV transmission. Most respondents (98.1\%) said that the use of male condoms prevents pregnancies. A further $98.1 \%$ of respondents reported that expired condoms burst easily when used. Some $84.8 \%$ of respondents indicated that a new condom must be used during each sexual encounter. A high percentage $(97.1 \%)$ of respondents reported that HIV-positive persons must always use a condom during sex. Most (98.1\%) respondents also reported that it is best for HIV-positive couples to use condoms to prevent HIV transmission between each other.

About $97 \%$ of respondents indicated that correct and consistent condom use means using a condom during every sexual encounter, and following the manufacturer's instructions.
Above half $(52.4 \% ; \mathrm{n}=55)$ of respondents obtained a score of more than $80 \%$, suggesting that they were knowledgeable about condom use, while $47.6 \%$ had insufficient knowledge.

\subsection{Attitudes towards the use of male condoms}

More than half $(54.5 \%)$ of respondents reported that male condoms tear easily. Most (84.0\%) respondents reported that male condoms are easier to use than female condoms. A larger percentage $(85.1 \%)$ of respondents disagreed that older men must not learn how to use a condom. Some $71.3 \%$ of respondents disagreed that men who use condoms have sex many times. Almost half $(51.1 \%)$ of respondents indicated that condoms which are distributed free of charge are of poor quality. Most (78.3\%) of respondents could not agree that distributing condoms at workplaces encouraged immorality.

In addition, most $(88.3 \%)$ respondents indicated that they are comfortable to ask for condoms from the health-care workers.

Some $94.7 \%$ of respondents indicated that it is correct for partners to ask one another to use condoms. The majority (86.2\%) could not agree that male condom use weakens the erection of the penis.

\subsection{Condom use}

Almost all (93.6\%) married respondents indicated that they used condoms. However, this difference was not statistically significant $(\mathrm{p}=0.689)$.

Almost all $(96.7 \%)$ respondents with tertiary education used condoms - more than those with secondary and primary education only $(93.5 \%$ and $93.1 \%)$. However, this difference was not statistically significant $(\mathrm{p}=0.785)$. Some $94.8 \%$ of unskilled respondents used condoms - more than the semi-skilled and skilled respondents $(92.9 \%)(\mathrm{p}=0.962)$. A high percentage $(93.0 \%)$ of respondents who lived in family houses reported using condoms more than respondents who lived in a single-sex hostel (86.9\%), but this difference was not statistically significant $(\mathrm{p}=0.568)$. Respondents who lived alone used condoms more $(90.1 \%)$ than those that lived with their partners $(87.5 \%)$. However, this difference was not statistically significant $(\mathrm{p}=0.712)$.

\subsection{Male condom use practices}

Most $(99.5 \%)$ respondents reported that they know how to use condoms and a high percentage $(89.5 \%)$ have used one. The prevention of HIV transmission was the commonest reason for why most respondents $(77.1 \%)$ used condoms.

More than half $(51.4 \%)$ of respondents reported that most older men may be using condoms.

\section{Discussion}

\subsection{Knowledge about male condoms}

The use of male condoms is a critical element in a comprehensive, effective and sustainable approach to HIV prevention and treatment (UNAIDS \& WHO, 2009). Therefore it is vital for sexually active individuals to have knowledge of condom use. This study established that the respondents' level of knowledge was moderate, with $52.4 \%$ having answered correctly to seven questions and more, and suggesting they were knowledgeable about male condom use. This finding concurs with the finding that $67 \%$ of NAMDEB general employees knew the importance of male condoms as an HIV-prevention strategy (Hyde, 2007).

Study subjects $(94.3 \%)$ also acknowledged male condoms as part of the ABC HIV-prevention strategy. What is more, $98.1 \%$ of respondents knew that male condom use prevent pregnancies and it thus can be used as a family-planning method. It is well established that condoms are $82-98 \%$ effective at preventing pregnancy, particularly when using water-based lubricants that do not damage condoms (compared to oil-based lubricants that weaken 
the condom, causing it to tear or break) (WHO, 2013). Previous research has indicated that condom use is not only important for family planning and reducing fertility indices, but is also a life saver in terms of preventing HIV infection. When properly used, male condoms are a proven and effective means for family planning and preventing transmission of HIV/AIDS and other Sexually Transmitted Infections (STIs) (MoHSS, 2011)

Nearly all $(98.1 \%)$ respondents suggested that expired condoms burst easily, with only $1.9 \%$ disagreeing. It can therefore be concluded that the respondents were aware of the risk involved in using expired condoms. Similar results were observed in a study that claimed that condoms are not $100 \%$ safe (Lemptey \& Gayle, 2001; World Bank, 2004) and that their safety depends on the handling and storage of the condom. Respondents' views on the use of condoms by HIV-positive persons were sought, and $97.1 \%$ of respondents agreed that HIV-positive individuals should always uses a condom. This demonstrates an understanding of the importance of using condoms - even already infected.

The importance of condom use for HIV-positive individuals is emphasised in order to avoid reinfection (Van Dyk, 2008). Reinfection means that a second viral strain can successfully establish infection, despite prior infection with another HIV strain. Nearly all $(98.1 \%)$ respondents said that HIV-positive couples "must always use condoms, to prevent further infection".

\subsection{Attitude toward male condoms}

A large percentage $(84.0 \%)$ of respondents agreed that male condoms are easier to use than female condoms. This concurs with the Namibia National Strategic Framework for HIV and AIDS Response (2010/11- 2015/16), which reported that both men and women have revealed difficulties in using female condoms, despite their apparent effectiveness (MoHSS, 2010).

Furthermore, $85.1 \%$ of respondents in this study clearly indicated they are aware that older men need to use a condom. However, the present results contradict the findings of a cross-sectional survey in Kenya (Kyobutungi et al 2009) that a large number (71.6\%) of men lacked knowledge of the personal risks relating to HIV/AIDS and thus do not use condoms. This study further showed that condom use among men decreases with age, perhaps as a result of not being concerned about STIs. Studies in Nigeria, Cameroon, Uganda, Zambia and Tanzania found that, in general, older men are less aware of effective preventive measures and are less knowledgeable about HIV-prevention measures than men aged 15 to 49 years. For example, in Nigeria, $68.9 \%$ of men aged 15 to 49 years knew that using condoms and having only one sexual partner are effective measures - as opposed to only $58.3 \%$ of men aged 50 to 59 years (Negin \& Cumming, 2010).

With regard to the present findings, it is disconcerting that $12 \%$ of respondents agreed with the statement that "Men of your age must not use condoms". This means that if they do not believe in using condoms at their age, they are more likely to engage in unprotected sex. These attitudes are not helpful in the prevention of HIV and AIDS and other sexually transmitted diseases. Thus, these findings call for new communication initiatives that target specific individuals and groups which are at risk - especially with regard to changing male behaviours and attitudes towards condom use. This is because negotiating safer sex may be unfamiliar to most older men and this can be blamed on the unavailability of health knowledge that targets them, even though they remain sexually active (Poyntena et al. 2013).

A positive attitude concerning male condom use is that $78.3 \%$ of the respondents did not think that distributing free condoms at the workplace encourages employees to engage in more sex. Even in the absence of research evidence, it is thought that refraining from sexual activities might be difficult. Thus, with Namibia being one of the countries with a generalised HIV epidemic, it is beneficial to ensure access to condoms at public places. This is even more important for NAMDEB - considering that a large number of its employees live away from their families, and there is no guarantee they will not get involved in temporary relationships.
In this study, a relatively small proportion (51.1\%) of respondents disagreed that free-of-charge condoms are of poor quality compared to $42.9 \%$ who were in agreement. The percentage of respondents agreeing is sufficient to cause concern, as their beliefs could prevent them from using workplace-provided condoms. Negative perceptions about free-of-charge condoms being of a poor quality were also reported in a previous study in Namibia (Muheua, 2006). It was reported they lack enhanced attributes such as dots and aroma. A similar perception was reported by the World Health Organization (MoHSS, 2010), which suggested that colour; smell and texture played an important role in the choice of condoms.

\subsection{Practice of male condom use}

In this study, respondents' total knowledge was analysed according to background details. The analysis clearly shows that most respondents $(89.5 \%)$ said they use condoms. The results show a surprisingly high number, compared to previous data concerning condom use in Namibia. For instance, the National Strategic Framework (NSF) (2010/11-2015/16) reported that condom use was still low and inconsistent (MoHSS, 2010). Moreover, the latest demographic and health survey did not report on the use of condoms in males aged 50 years and above: the section on condom use focused on younger population groups below the age of 49 years.

The results of this study are in fact encouraging. This is contrary to the findings of the study conducted at the mining site in Ethiopia, which revealed that HIV-preventative behaviour of the mining workers was low and consistent condom use among these mining workers was low - even though they are reported to have much sexual intercourse with commercial sex workers (Abdissal et al, 2014). In addition, a study at South African mines revealed a lower percentage $(18.5 \%)$ of condom use during last sexual intercourse. This is despite the high prevalence rate of HIV, large numbers of mine workers not knowing their HIV status, uncircumcised men, and multiple sex partners (Baltazar et al. 2015).

With regard to the reasons why respondents in this study were likely to use a condom, most (77.1\%) gave 'to prevent HIV', and $(10.5 \%)$ 'to prevent pregnancy' as the reasons. This shows that the respondents are aware of the threat of HIV. It is anticipated that this awareness would lead to condom use among the respondents.

\section{Recommendations}

The study revealed a satisfactory attitude towards male condom use. However, it showed some gaps in some variables - i.e. $54.5 \%$ of respondents reported that male condoms tear easily and $51.1 \%$ indicated that condoms distributed freely are of poor quality. Nevertheless, those gaps can be addressed through intensive education and awareness interventions that are age-specific and sensitive. In order for NAMDEB to improve the knowledge of condom use, and ultimately actual condom use - particularly among the elder segment of the employee population - the education and awareness classes should promote and clarify the value and effectiveness of male condoms as important tools of HIV prevention. Moreover, current peer education programmes should also recruit and train those aged above 50 as peer educators. In addition, condom campaign messages must be translated into the indigenous languages - e.g. Oshiwambo, Damara/Nama and Afrikaans. The marketing of condoms must also be conducted in an innovative and appealing manner to men aged 50 years and above. A qualitative enquiry is recommended in order to explore perceptions of males aged 50 years and above, on the quality and distribution of free-of-charge condoms.

\section{Conclusion}

This study looked to assess the knowledge, attitudes and practices of male condom use among NAMDEB employees, 50 years and 
older. The respondents' knowledge about male condoms appeared to be moderate, as only $52.4 \%$ responded correctly to more than eight of the nine questions about knowledge of condom use. The findings of the study lead to the suggestion that there might be older NAMDEB employees who may not appreciate the distribution of condoms on a free-of-charge basis, and therefore they may not be using such condoms - hence the risk of unprotected sex.

\section{References}

[1] The World Bank. Battering HIV/AIDS. A decision makers' guide to the procurement of medicines and related suppliers. C2004 [cited 2016 October 05]. Available from: http://documents. worldbank.org/curated/en/573861468762607386/ pdf/297070PAPER0Battling0HIV0Aids.pdf

[2] Joint United Nations Programme on HIV/AIDS (UNAIDS) and World Health Organization (WHO). 2009 AIDS epidemic update C2009 [cited 2016 October 05]. Available from: http://data.unaids.org/pub/Report/2009/JC1700_Epi_Update_2009 en.pdf

[3] World Health Organization (WHO). Global Health Observatory data: HIV/AIDS. C2016 [cited 2016 October 05]. Available from http://www.who.int/gho/hiv/en/

[4] Ministry of Health and Social Services (MoHSS). Surveillance Report of the 2014 National HIV Sentinel Survey. c2014 [Cited 2016 October 05]. Available from: http://www.mhss.gov.na/files/downloads/12f_2014\%20National\%2 0HIV\%20Sentinel\%20Survey.pdf

[5] Joint United Nations Programme on HIV/AIDS (UNAIDS). AIDS Info: AIDS related deaths. C2016 [Cited 2016 October 05]. Available from: http://aidsinfo.unaids.org/

[6] Ministry of Health and Social Services (MoHSS) and Namibia Statistics Agency (NSA). Namibia demographic and health survey 2013. C2013 [Cited 2016 October 05]. Available from: https://dhsprogram.com/pubs/pdf/FR298/FR298.pdf

[7] Rivers, K., and Aggleton, P. 1999, Men and the HIV epidemic. Thomas Coram Research Unit, Institute of Education. University of London

[8] Lamptey, PL \& Gayle, H.D. Editors. HIV/AIDS prevention care in resource constrained settings: A handbook for the design and management of programs. C2001 [Cited 2016 October 06]. Available from:

http://www.forcedmigration.org/sphere/pdf/common/fhi/hivaidsprevention-care.pdf

[9] Pedian, N.S., Buve, A., Balkus, J., Serwadda, D. \& Cates, W. Biomedical interventions to prevent HIV infection: Evidence, challenges and way forward. 2008 August 16; 372(9638): 585-99. http//dx.doi.org/10.1016/S0140-6736(08)60885-5

[10] Grotzinger, E. Employees' knowledge, attitude and practices relating to HIV/AIDS at a mining company in Namibia. [unpublished dissertation]. Cape Town: University of the Western Cape; 2006.

[11] Hyde, S. \& Associates. (2007). Knowledge, attitudes and practices of HIV/AIDS among NAMDEB employees and contractors. Johannesburg, South Africa: Susan Hyde \& Associate.

[12] Bollinger, L. \& Stover, J. The economic impact of AIDS in South Africa. C1999 [Cited 2016 October 06]. Available from: http://www.policyproject.com/pubs/seimpact/seimpact africa.pdf

[13] Maree, K., Editor. First steps in research. Pretoria: Van Schaik; 2016.

[14] De Vos, A.S., Strydom, H., Fouche, C.B. \& Delport, C.S.L. Research at grass roots for the social sciences and human service professions. Pretoria: Van Schaik; 2011.

[15] Hyde, S. \& Associates. Knowledge, attitudes and practices of HIV/AIDS among NAMDEB employees and contractors. Johannesburg: Hyde, S. \& Associates.

[16] World Health Organization (WHO). Male Latex Condom: Specification, Prequalification and Guidelines for Procurement. C2013 [Cited 2016 October 06]. Available from: http://apps.who.int/iris/bitstream/10665/44383/1/9789241599900 e ng.pdf

[17] Ministry of Health and Social Services (MoHSS). Namibian treatment guidelines. C2011 [Cited 2016 October 08]. Available from: http://www.mhss.gov.na/files/downloads/f88 Namibia\%20Standar d\%20Treatment\%20Guidelines\%202011.pdf

[18] Muheua, A. A description of the perceptions and barriers that influence initial and consistent use of condoms amongst a sample of male and female students of the Polytechnic of Namibia. [Un- published dissertation]. Cape Town: University of the Western Cape; 2006.

[19] Van Dyk, A.C. HIV/AIDS care and counselling: A multidisciplinary approach. Johannesburg: Pearson South Africa; 2008.

[20] Ministry of Health and Social Services (MoHSS). Namibia National Strategic Framework for HIV and AIDS Response (2010/112015/16). c2010 [cited 2016 October 06]. Available from: http://www.ilo.org/wcmsp5/groups/public/---ed protect/---protrav/--ilo aids/documents/legaldocument/wcms 301802.pdf

[21] Kyobutungi, C., Ezeh, A.C., Zulu, E. \& Falkingham, J. HIV/AIDS and the health of older people in the slums of Nairobi, Kenya: Results from a cross sectional survey. BMC Public Health. 2009; (9): 153. Available from: https://doi.org/10.1186/1471-2458-9-153.

[22] Negin, J. \& Cumming, R.G. HIV infection in older adults in subSaharan Africa: Extrapolating prevalence from existing data. C2010 [Cited 2016 October 06]. Available from: http://www.scielosp.org/pdf/bwho/v88n11/v88n11a14.pdf

[23] Negin, J., Mills, E.T. \& Barnighausen, T. Aging with HIV in Africa: The challenge of living longer. AIDS. 2012; 26(1): 1-5. Available from: https://doi.org/10.1097/QAD.0b013e3283560f54.

[24] Poyntena, M., Grulicha, A.E. \& Templeton, D.J. Sexually transmitted infections in older population. Curr Opin Infect Dis; 2013; 26: $80-85$. Available https://doi.org/10.1097/QCO.0b013e32835c2173.

[25] Abdissal, H.G., Lemu, Y.K. \& Nigussie, D.T. HIV preventive behavior and associated factors among mining workers in Sali traditional gold mining site bench maji zone, Southwest Ethiopia: A cross sectional study. C2014 [cited 2016 October 06]. Available from: http://www.biomedcentral.com/1471-2458/14/1003

[26] Baltazar, C.S., Horth, H., Inguane, C., Sathane, I. , Ce'sar, F., Ricardo F., Botão, F., Augusto, A., Cooley, L., Cummings, B., Raymond, H.F. \& Young, P.W. HIV prevalence and risk behaviors among Mozambicans working in South African mines. AIDS Behav. 2015; 19: 59-67. Available from: https://doi.org/10.1007/s10461-014-0941-6. 